\title{
The Germans from Russia:
}

\section{Documenting the Immigrant Experience \\ in Northern Colorado}

\author{
Dawn E. Bastian
}

\begin{abstract}
The Sidney Heitman Germans from Russia Collection at the Colorado State University Libraries is named in honor of the late Dr. Heitman's years of research and teaching about Colorado’s second largest ethnic group. Created to support his Germans from Russia in Colorado Study Project, active at the university in the late 1970s, the collection's centerpiece is the oral histories generated by the project. This article provides information on the collection and describes a digital project supported by an Institute of Museum and Library Services (IMLS) grant through the Colorado Digitization Project (CDP) to make a selection of the oral histories, transcripts, photos, project documentation, and the finding aid available online to researchers. In addition to
\end{abstract}

Dawn E. Bastian, MA, is Coordinator for Metadata and Digital Services, Morgan Library, Colorado State University, Fort Collins, Colorado (E-mail: dawn.bastian@colostate.edu). She served as Co-Principal Investigator for the project Western Trails: Germans from Russia on the Trail to Colorado, funded by the Institute of Museum and Library Services through the Colorado Digitization Project.

This article is based on a presentation given at the 2004 Annual Meeting of the Society of American Archivists in Boston, Massachusetts. 
providing access to more than 1,500 digital objects, project staff developed important metadata for their discovery, retrieval, and management using the Western States Dublin Core Metadata Best Practices and Encoded Archival Description (EAD).

KEYWORDS. Sidney Heitman Germans from Russia Collection, Colorado State University Libraries, digital projects, Institute of Museum and Library Services, IMLS, Colorado Digitization Project, CDP, oral histories 
According to the 2000 census, approximately 43 million Americans are descended from German immigrants who arrived in the United States over a three-hundred-year period. At 15.2 percent of the total population of 281 million, they are easily the largest single American ancestral group. ${ }^{1}$ One of the most interesting and least known subgroups is the so-called "Germans from Russia” or "German Russians" who immigrated to the United States during the late nineteenth and early twentieth centuries.

\section{HISTORY}

The Germans from Russia, products of a double migration, first entered Imperial Russia during the second half of the eighteenth and first quarter of the nineteenth centuries at the invitations of Catherine the Great and her grandson Alexander I, respectively. ${ }^{2}$ Weary from losses suffered during the Seven Years’ War (1756-1763), political and religious turmoil, and economic depression, thousands from various parts of divided Germany settled in the Volga River valley, the Black Sea territories, Bessarabia, the province of Volhynia, the Crimea, the Caucasus, and Siberia. These farmers and artisans were expected to colonize newly-acquired lands, contribute to commercial and agricultural development, and serve as progressive role models for the Russian peasantry. ${ }^{3}$

For over a century, the Germans from Russia prospered in their adopted country and enjoyed a privileged status. This included religious freedom and self-government, exemption from involuntary civil and military service, and use of their language and 
customs. In 1871, however, Alexander II adopted measures that compelled these German colonists to seek new lives elsewhere. As part of his desire to modernize and integrate his vast empire, he suspended their right to self-government and served notice that GermanRussian youth would be conscripted into the military. In 1880, the Russian language became mandatory for instruction in German-Russian schools for all subjects except religion and German. These alarming threats to personal liberty were compounded by the effects of a rapidly growing population, limited availability of arable land, the droughts of 1873 and 1875, and declining agricultural prices. Faced with this combination of political, social, and economic distress and enticed by news of the Homestead Act in the United States and similar legislation in other countries in North and South America, many Germans from Russia viewed the acquisition of land elsewhere as the solution to their tribulations. ${ }^{4}$

Commencing in 1873, the wave of German-Russian immigration to the New World peaked in 1912, ceased during the First World War, resumed in the early 1920s, and waned following the restrictive United States Immigration Act of 1924 (the JohnsonReed Act), which sharply reduced quotas for Eastern and Southern Europe. ${ }^{5}$ Sporadic migrations continued until after the Second World War. ${ }^{6}$ Between 1870 and 1914, German-Russians who came to the United States numbered approximately $116,000^{7}$ and were comprised of three major groups: the Volga Germans, the Black Sea Germans, and the Mennonites. ${ }^{8}$ While other American immigrants, such as the Poles and Italians, congregated in large cities, the Germans from Russia settled primarily on the rural plains and prairies of the Midwest, where topography and climate are similar to those of the steppes they left behind. 
The story of this second great migration--and of those who remained in Russia and suffered the tragedies of wars, revolutions, forced collectivization, famines, deportations, and Soviet communism--has begun to be told and studied during recent decades. Descendants of Germans from Russia are eager to promote historical and genealogical research, preserve and disseminate information on German-Russian culture, and foster connections within their community and beyond. They have formed their own heritage societies and organizations such as the American Historical Society of Germans from Russia (AHSGR) and the Germans from Russia Cultural Preservation Foundation (GRCPF). Many scholars have focused their attention on the German-Russians; and in 1975, Dr. Sidney Heitman established the Germans from Russia in Colorado Study Project at Colorado State University’s (CSU) Department of History, the first universitysponsored research and study program of its kind. ${ }^{9}$

Colorado was the logical site for this program because it has one of the country's largest concentrations of German-Russians--primarily Volga Germans--who form its second largest ethnic group after Hispanics. Drawn to Colorado from Kansas and Nebraska by available homestead lands and employment with the railroad, they began arriving in the 1880s. Greater numbers came in the first decade of the early twentieth century from neighboring states and Russia with the emergence of the sugar beet growing and processing industries of which they became the mainstay. As resident Colorado farmers were unwilling to perform the arduous manual labor that beet cultivation required, sugar agents sought an imported work force; German-Russians with large families proved to be exemplary workers. ${ }^{10}$ Transitioning eventually from laborer to renter to land or business owner, Colorado’s hardy, industrious, and ambitious German- 
Russians became important contributors to the state's transformation from a rugged, untamed frontier to the prosperous, modern entity that it is today. Swept forward by assimilation and acculturation, they filled leading positions in commerce, education, politics, and culture within two generations. While socioeconomic progress and success did not come easily or to all Germans from Russia, many others and their descendants unquestionably experienced a rapid and striking rise in mobility in Colorado and elsewhere. ${ }^{11}$

\section{THE SIDNEY HEITMAN GERMANS FROM RUSSIA IN COLORADO}

\section{COLLECTION}

Dr. Heitman’s Germans from Russia in Colorado Study Project was a four-year effort by more than ten project staff members whose responsibilities ranged from researcher to archivist to consultant. Building upon the work already underway for years by the American Historical Society of Germans from Russia, the study project consisted of five objectives: 1) research, including a comprehensive study of Colorado’s GermanRussians; 2) teaching and training; 3) publication and dissemination of information; 4) historic preservation; and 5) public service. Among its achievements was the creation of a special archival and bibliographic collection of materials to support research and teaching on German-Russians at Colorado State. The collection includes oral history interviews and transcripts, project files, conference papers, undergraduate student research, clippings, photographs, slides, sound recordings, books, journals, maps, government publications, and family histories.This collection was named the Sidney Heitman Germans from Russia Collection in his honor in 1993. 
The centerpiece of the collection is the oral history interviews with primarily older members of the German-Russian community recorded by study project staff. Collected between 1975 and 1978, when their stories were in danger of being lost to the ravages of time, these sixty interviews recorded on analog cassette tapes provide the listener with specific accounts of many individuals--their lives in Russia and Colorado, experiences as immigrants, and their thoughts, feelings, and fears, daily labors in the beet fields, family and personal relationships, cultural perspectives, conflicts, and customs that are too seldom incorporated into historic text.

In early 2002, staff members of the Colorado State University Libraries were delighted to learn that we would receive funding from an Institute of Museum and Library Services (IMLS) National Leadership Grant in the area of Library and Museum Collaborations to contribute to a digital collection of primary resources and special collection materials on the topic of western trails. This funding was made available through the Colorado Digitization Project (CDP) ${ }^{12}$ to a group of archives, libraries, historical societies, and museums in Colorado, Kansas, Nebraska, and Wyoming that participated in the CDP's Western Trails Project. As stated in the grant proposal the CDP submitted to IMLS, the Western Trails Project will present on the Web “a multifaceted/interdisciplinary approach to trails including samples of trails, why trails developed, what motivated people to follow the trails, and other perspectives relating to the trails, including Western Trails in literature, the role of health and water in development of the trails, etc.” 13 
By the close of the IMLS one-and-a half year funding cycle in September 2003, we successfully met our overall project goal to develop, maintain, and preserve a digital collection of primary resource materials on the Germans from Russia to support campus and research needs in history, and interests of local and regional residents. As participants in the Western Trails Project, we also assisted in developing common standards for digitization and metadata application within a collaborative environment, and demonstrated that the CDP model for digital project collaboration could be adapted for a multi-state initiative by a range of cultural heritage institutions.

\section{THE DIGITIZATION PROCESS}

Materials selected for digitization from the Sidney Heitman Germans from Russia Collection include seventy-four cassette tapes of sixty oral history interviews, twenty oral history transcripts consisting of 1,328 pages, 142 pages of Germans from Russia Study Project documents, and twenty-one black and white photographs. We also digitized five hand-drawn linen maps created by young frontier soldier and artist Caspar Collins, featuring river crossings, government forts, and telegraph stations once found in areas of the western plains where Germans from Russia later settled or passed through on their migrations farther west. The latter are not part of the Germans from Russia collection but one of the unique and outstanding holdings of the Archives and Special Collections Department. The Web site presents fifty-one excerpts from the twenty oral histories with accompanying transcripts, the transcripts in their entirety, the photographs, the study project documents, the full-text finding aid for the entire archival collection marked up 
using Encoded Archival Description, and the Caspar Collins maps (see Figures 1 and 2). ${ }^{14}$

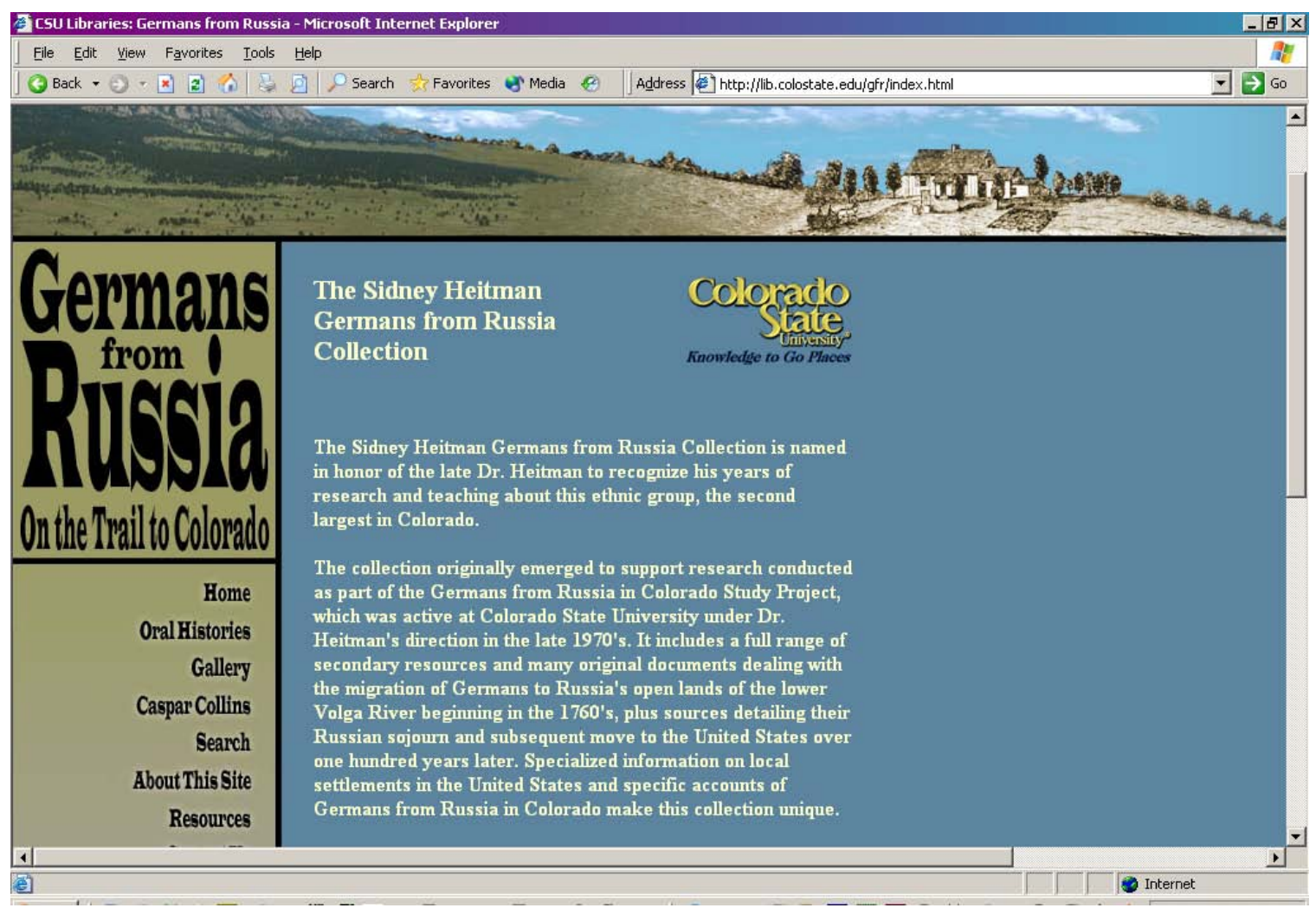

All screen shots courtesy of Colorado State University’s Sidney Heitman Germans from Russia Collection.

Figure 1. The Sidney Heitman Germans from Russia Collection Home Page 


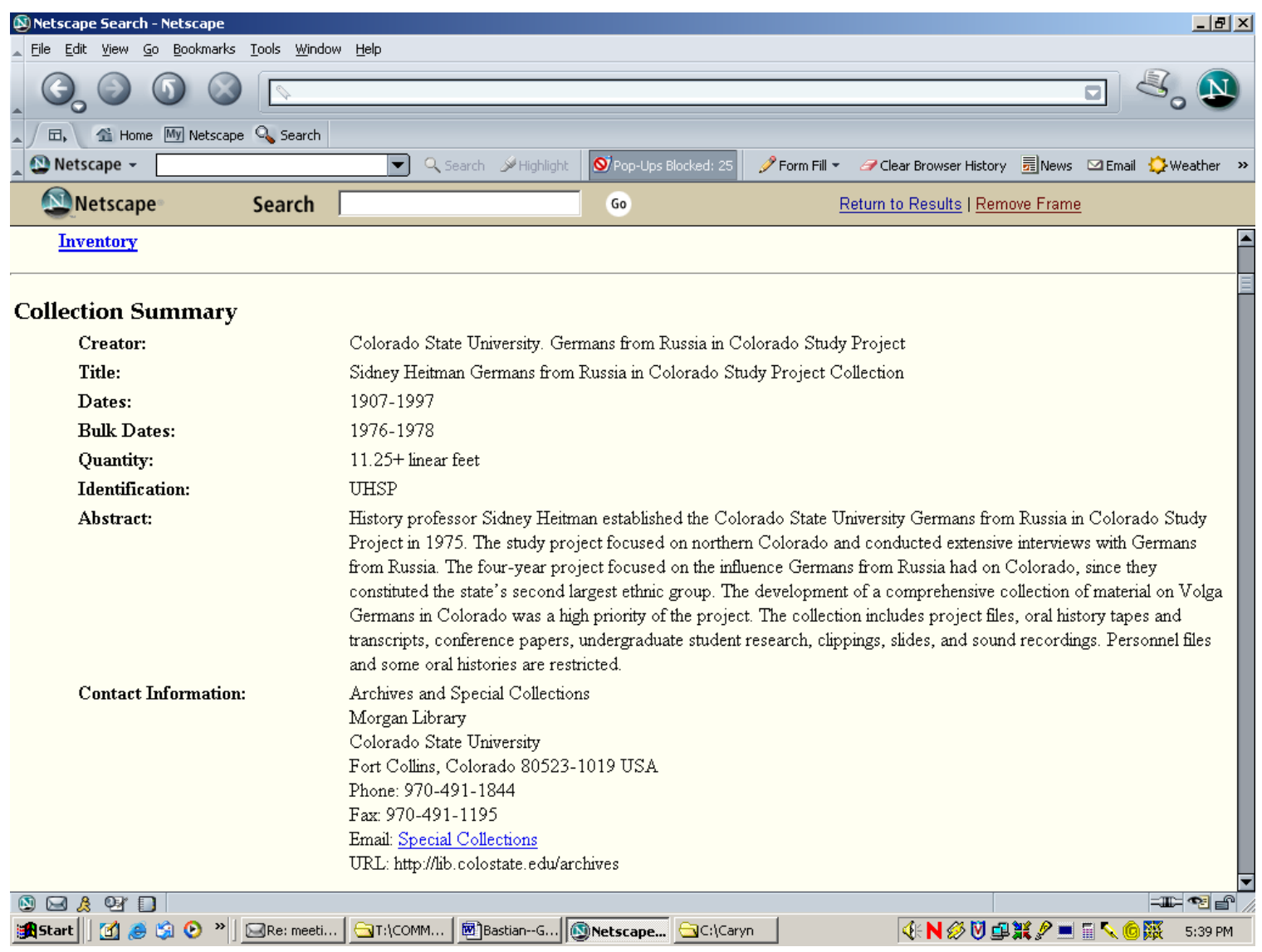

Figure 2. Finding Aid for the Sidney Heitman Germans from Russia in Colorado Study Project Collection

Our greatest challenge was converting the analog audio oral history tapes to digital format. Standards for this evolving technology and reformatting procedures were neither numerous nor well defined. In addition, the libraries did not possess the equipment necessary for conversion. A visual assessment by the Coordinator for Preservation Services suggested while the nearly thirty-year-old tapes were probably not fragile, their true condition was initially uncertain.

We were also concerned about making the transcripts and excerpts of the oral histories available electronically to a worldwide audience. Each interviewee signed the 
necessary release forms long before it was possible to publish such material on the Web. Although all were likely deceased, we thought their families might object to the exposure the interviews would receive because of privacy reasons and other issues. To allay our discomfort, we consulted our faculty project advisor a second time regarding this issue. The advisor, a history professor who was an active participant in the Germans from Russia in Colorado Study Project and conducted many of the interviews, assured us that all interviewees wanted to make their stories available to interested researchers and that he was comfortable with our plans. We also placed a statement on the Web site inviting relatives of those whose information is included to contact us if they wish to discuss any concerns (see Figure 3).

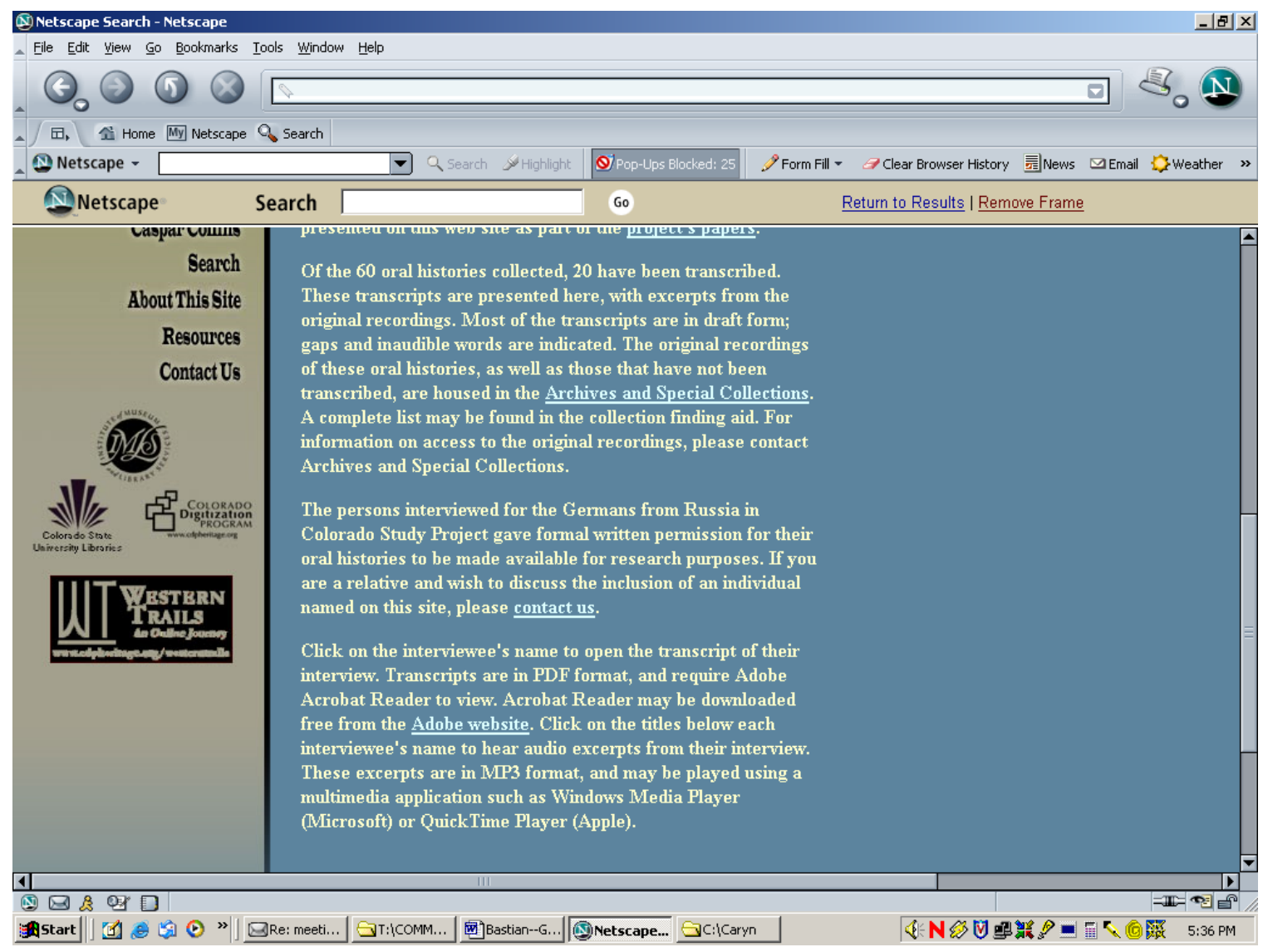

Figure 3. Oral History Page with Invitational Statement to Relatives of Interviewees 
We chose to outsource the digital audio conversion after securing quotes from several vendors, including the University's Office of Instructional Services. The Mediawerx Corporation in Colorado Springs was selected based on expertise, price estimate comparisons, and a recommendation secured from another Western Trails Project participant who had worked with the company previously. A set of conversion requirements was developed based on information gathered from the CDP workshop "Introduction to Digital Audio,"15 the draft of CDP’s Digital Audio Best Practices, ${ }^{16}$ version 1.2 and Mediawerx, which recommended conversion of the analog audio to AIFF files because of possible data degradation problems with WAV files. The company performed a test conversion which demonstrated the tapes were in good condition and the digital product was of excellent quality.

The audio conversion went smoothly and according to schedule. Cassette tapes were hand-delivered to the vendor for reasons of time, cost, and security. The digitized files from the first delivery were compared carefully to the original tapes to verify quality further. Subsequent deliveries were spot-checked. One CD was created for each tape, containing one AIFF file per side. Since the sound quality of the analog tapes was consistently very high, no cleanup or modification of the audio was considered necessary. A DVD-ROM back-up copy of each file was made at the conclusion of the conversion. Mediawerx recorded the technical metadata we needed as part of the conversion process based on a list developed by our metadata librarian, including hardware, software, file size, type, naming convention, and date of conversion. 
Access files for the digital audio were created in-house. For reasons of privacy ${ }^{17}$ and technical ease-of-use, excerpts were used instead of entire audio files, which are quite large, to create access files. Only oral histories with accompanying transcripts were excerpted. Excerpts were selected by reviewing the transcripts and selecting portions for audio review. These "candidate excerpts" were reviewed for audibility and coherence by listening to the digitized master files. For example, while the sound quality of the tapes was good, in some cases the speakers could not be clearly heard. In other instances, the speakers were hesitant or hard to follow, which made the audio difficult to understand. Sonic Foundry Sound Forge was used to copy acceptable excerpts from the AIFF original and convert them to MP3 format to create the final access file.

Transcripts were scanned in-house according to the Western States Digital Imaging Best Practices ${ }^{18}$ version 1.0 and saved in TIFF format. Optical character recognition (OCR) was performed by opening the TIFF files in Scansoft's OmniPage Pro and using its blocking and OCR tools. The results were saved as Microsoft Word documents. The transcripts were proofed in Word using photocopies of the originals for comparison. ${ }^{19}$ Word was used to correct any OCR errors, incorporate handwritten corrections and notes from the original transcript into the text, and add notes to indicate inaudible portions or areas where the transcription was unclear. The corrected Word files were then converted into PDF format to create the final access versions (see Figure 4). Because of time and budget constraints, transcripts were not compared to the original tapes or digitized audio files. 


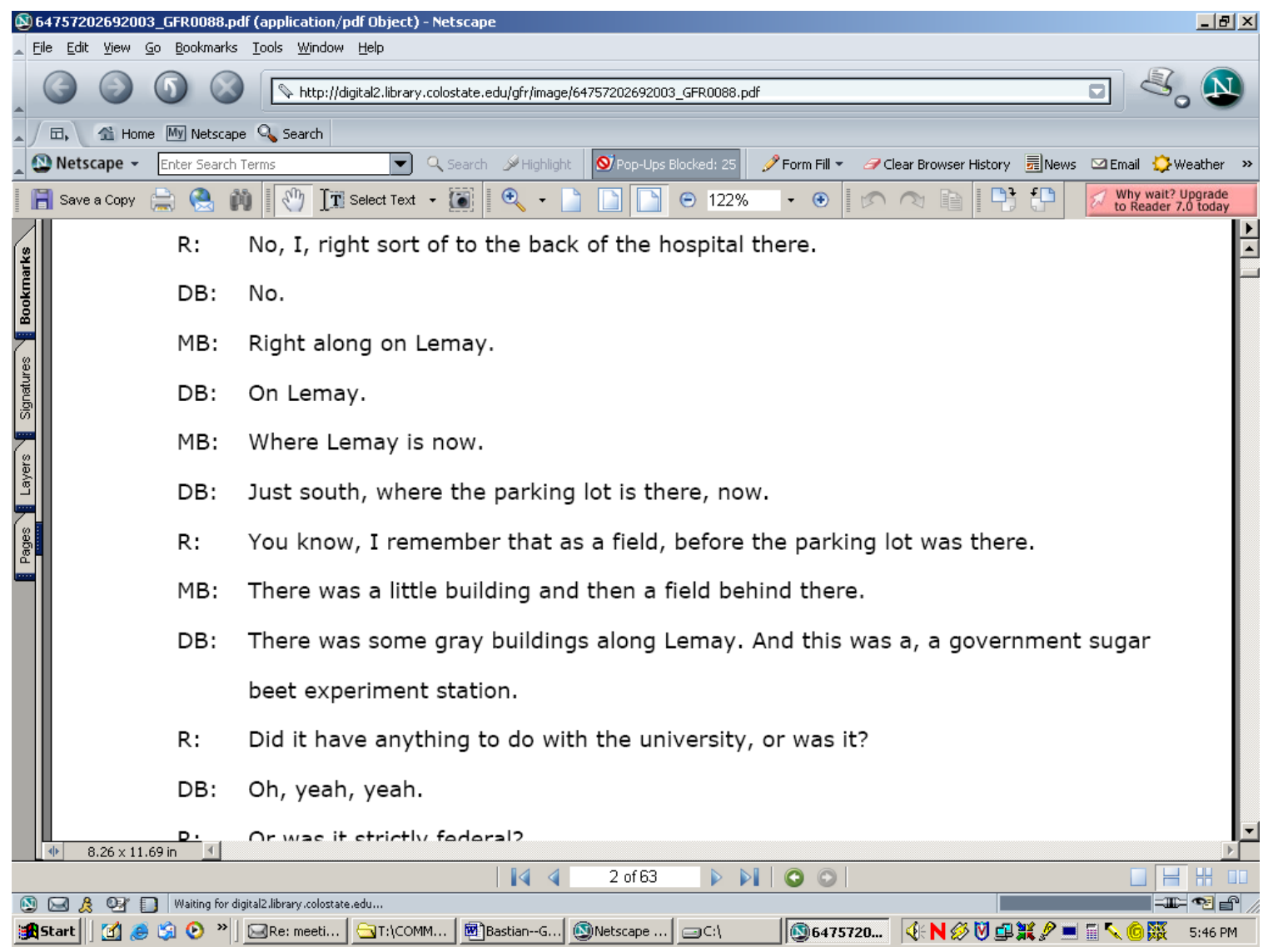

Figure 4. Transcript from Oral History Interview

The photographs were also scanned in-house using the same standard as the transcripts. Adobe Photoshop and Lasersoft Silverfast were used to capture images from an Epson flatbed scanner. Access JPEG images were then created in Photoshop from the TIFF masters (see Figure 5). 


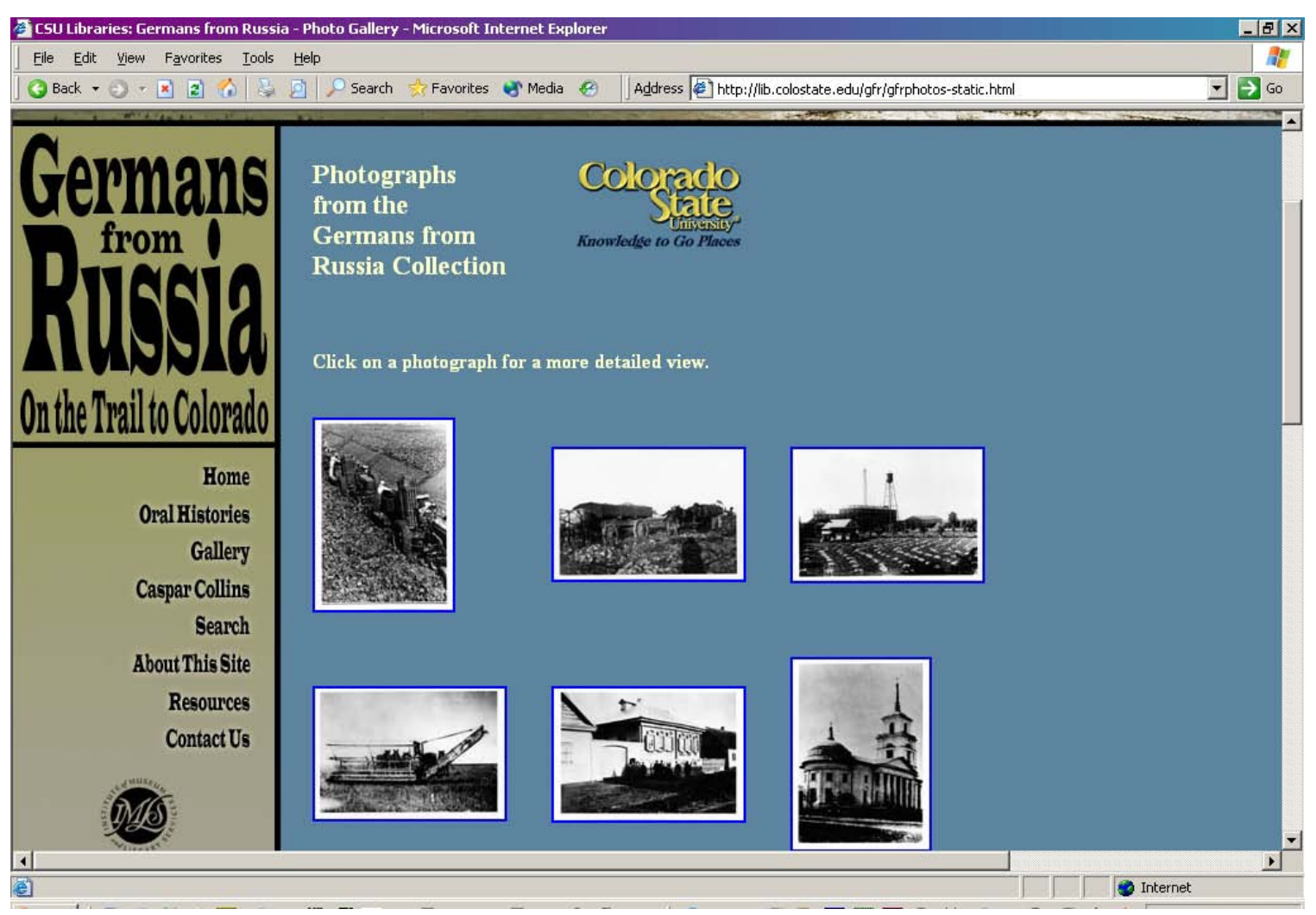

Figure 5. Photographic Images Page

Digitization of the Caspar Collins maps was performed by Colorado State's Office of Instructional Services (OIS), which has provided high-quality services to the libraries for its International Poster Collection. Since OIS is located on campus, transport of the large and fragile maps was simplified and libraries Preservation Services Department staff could oversee handling. The images were photographed, not scanned, using a Leaf Volare digital camera. Then they were converted from the Leaf Volare proprietary format to TIFF format using Adobe Photoshop and written to CDs. Adobe Photoshop was also used to convert the TIFF images to JPEG and adjust image size and resolution to create the access and thumbnail images (see Figure 6). 


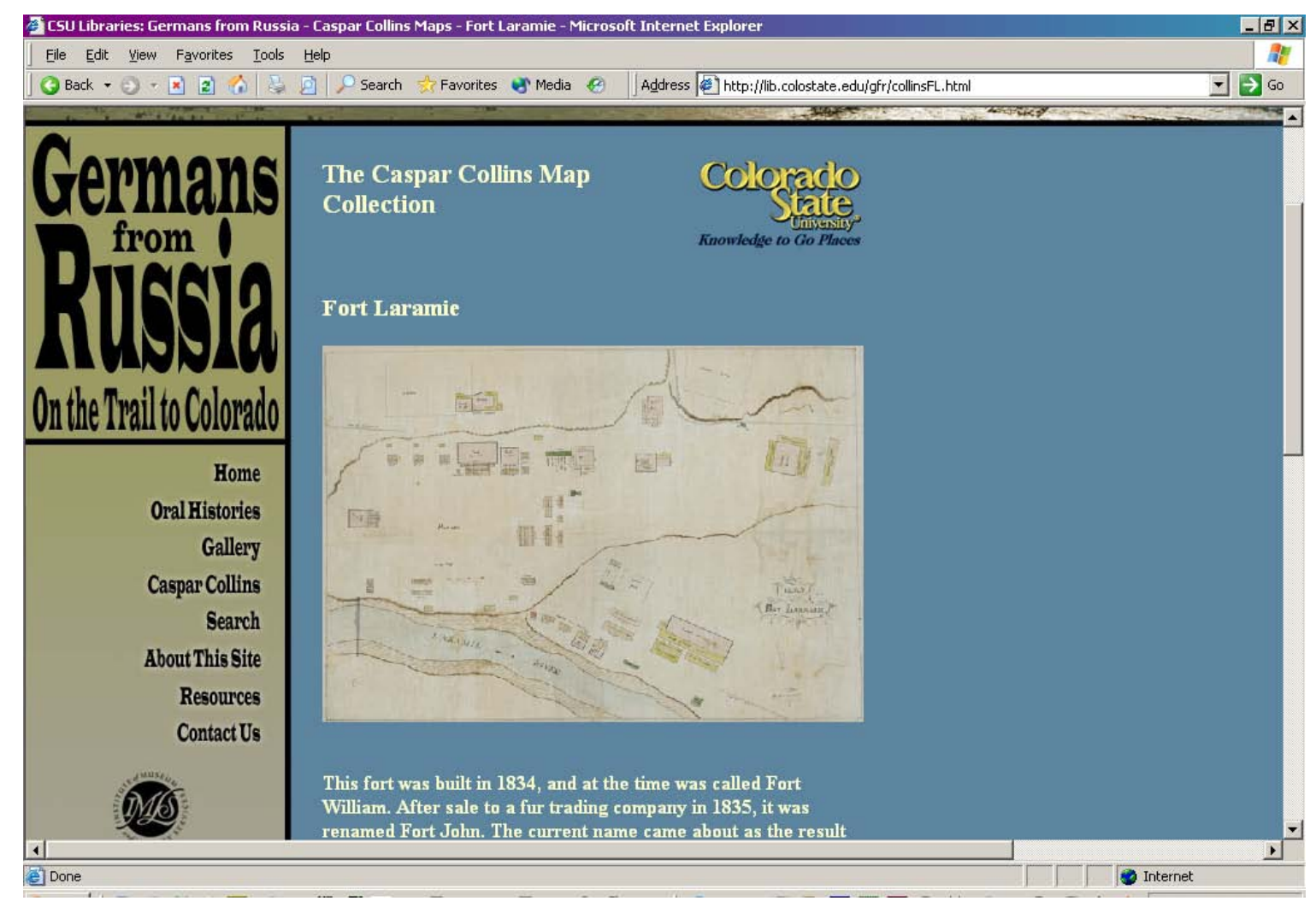

Figure 6. Digitized Map from the Caspar Collins Map Collection

Rich metadata was developed for each digital object to facilitate discovery, retrieval, and management. Several standards and documents served as a guide for metadata creation, including CDP's Western States Dublin Core Metadata Best Practices ${ }^{20}$ version 1.2 and Digital Audio Best Practices version 1.2, the LC/NACO Authority File, the Anglo American Cataloging Rules $2^{\text {nd }}$ edition, 2002 revision, and Library of Congress Subject Headings (LCSH). Although LCSH has its limitations, and authority control is labor intensive, we were committed to using a controlled vocabulary of subject terms and consistent forms of personal, corporate, and geographic names because of the valueadded aspect for the researcher. Enhancements and customizations were made to the metadata to reflect the unique character of the collection and increase accessibility. While basic Dublin Core is comprised of fifteen elements and Western States Dublin Core 
eighteen elements, the Dublin Core metadata defined for the Germans from Russia Collection has twenty-nine elements.

All digital objects are stored with accompanying metadata in the CONTENTdm ${ }^{\circledR}$ digital asset management system. This XML database adheres to the principles of open source file formats, metadata fields, and Open Archives Initiative provider standards. The Germans from Russia Collection is retrievable at the item level by performing keyword or advanced searchers through the Web interface.

In addition to digital object access, the Germans from Russia Web site provides links to other sites related to the Germans from Russia and digital copies of papers from the original study project that the Germans from Russia Collection was created to support. The site also provides historical and biographical information on Caspar Collins and the places he mapped, and links to other sites and a bibliography of published sources about him. A collection-level record provides access to the Web site through the libraries' online catalog.

\section{CONCLUSION}

This grant project has greatly impacted our institution in positive ways. The incorporation of sound into the Web site has positioned the CSU Libraries to participate in a second grant project involving audio digitization and has identified us as providing access to digital objects via the Internet regardless of format. Development of the online Sidney Heitman Germans from Russia Collection has promoted awareness of Colorado State University Libraries as an important resource in the research on Germans from Russia. Following the release of the Web site and several presentations, we received 
enthusiastic and complimentary e-mail communications from both scholars and descendants of Germans from Russia, including relatives of some of the interviewees, and offers of additional content for both the archival and digital collections. One individual indicated an interest in donating funds for further development of the Web site and expansion of the curriculum to include a Germans from Russia study program. In addition, the accessibility of the digital collection and online finding aid has resulted in awareness of the range of materials available and a resurgence of interest in the archival collection, as evidenced by an increase in use by local and international scholars and area residents. One researcher who learned of the collection via the Web earned an important preservation award from the community this past spring for his work on a local historic survey project related to the Germans from Russia in Fort Collins.

The project has also provided the Libraries the opportunity to raise its profile on campus as a provider of digital services. We established an excellent working relationship with the Department of History on the digital landscape and created an online presence for its remarkable study project. One of our greatest pleasures was hearing our faculty project advisor express his deepest appreciation that the oral histories and other study project materials are now readily available to an international audience.

Our work with oral histories and digital audio was a new experience from which we gained valuable knowledge and recognition. The impact of a digital project can be afar greater than achievement of its stated goals. We have generated positive publicity for both the University and the Libraries, attracted donor support for one of our archival collections, built synergy with the local community, and greatly expanded skills of Libraries staff. And, finally, we are proud that we have helped raise consciousness about 
the Germans from Russia, a lesser-known immigrant group whose impressive achievements have contributed so much to Colorado and other parts of our great nation.

\section{NOTES}

\section{U.S. Census Bureau, “American FactFinder,”}

http://factfinder.census.gov/home/saff/main.html?_lang=en (accessed June 15, 2005).

2. Catherine’s manifesto, issued on July 22, 1763, offered invited colonists incentives such as generous grants of land and exemption from taxation for thirty years. An English translation of the complete text can be found in Karl Stumpp, The Emigration from Germany to Russia in the Years 1763 to 1862 (Lincoln, NE: American Historical Society of Germans from Russia, 1973), 15-18.

3. Sidney Heitman, ed., Germans from Russia in Colorado (Fort Collins, CO: Western Social Science Association, 1978), 1.

4. Kenneth W. Rock, Germans from Russia in America: the First Hundred Years (Fort Collins, CO: Germans from Russia in Colorado Study Project, Dept. of History, Colorado State University, 1976), 2.

5. Annual quotas for each nationality were based on a percentage of the number of foreign-born persons of that national origin recorded in the 1890 census. Since most immigrants from Eastern and Southern Europe arrived in the United States after that date, this was a calculated effort to restrict the flow of immigrants from those regions. See American Social History Project/Center for Media and Learning, City University of New York, and the Center for History and New Media, George Mason University, "History 
Matters: the U.S. Survey Course on the Web,”

http://www.historymatters.gmu.edu/d/5078 (accessed June 15, 2005).

6. Kenneth W. Rock, “'Unsere Leute’: the Germans from Russia in Colorado.” The Colorado Magazine, 54, 2 (Spring 1977): 159.

7. Kenneth W. Rock, Germans from Russia in America: the First Hundred Years (Fort Collins, CO: Germans from Russia in Colorado Study Project, Dept. of History, Colorado State University, 1976), 2.

8. Ibid., 3.

9. Sidney Heitman, ed., Germans from Russia in Colorado (Fort Collins, CO: Western Social Science Association, 1978), 2.

10. Beet cultivation was once viewed as ideal for children because it required much handwork.

11. Kenneth W. Rock, “'Unsere Leute’: the Germans from Russia in Colorado.” The Colorado Magazine 54, 2 (Spring 1977): 176-177.

12. The Colorado Digitization Project became the Colorado Digitization Program and is now called the Collaborative Digitization Program.

13. The full IMLS grant application can be viewed at: http://www.cdpheritage.org/westerntrails/documents/imls_westerntrails_2001.pdf

14. See the digital Sidney Heitman Germans from Russia Collection and the Caspar Collins maps at http://lib.colostate.edu/gfr/

15. The Introduction to Digital Audio workshop presentation can be viewed at: http://www.cdpheritage.org/resource/audio/documents/digaudio_ppt.pdf 
16. The Digital Audio Best Practices document is available at:

http://www.cdpheritage.org/resource/audio/documents/CDPDABP_1-2.pdf

17. The use of individual names is permanently restricted for some of the oral histories.

18. See the Western States Digital Imaging Best Practices document at: http://www.cdpheritage.org/resource/scanning/documents/WSDIBP_v1.pdf

19. As part of this process, the transcripts were aligned as closely as possible with the British National Library Sound Archive Style Sheets for Transcription of Oral History Tapes.

20. Version 1.0 of the Western States Dublin Core Metadata Best Practices has been superseded by version 2.0, which can be viewed at:

http://www.cdpheritage.org/resource/metadata/documents/WSDCMBP.pdf

\section{SELECTED BIBLIOGRAPHY}

\section{Books and Journals}

Heitman, Sidney, ed. Germans from Russia in Colorado. Fort Collins, CO: Western Social Science Association, 1978.

Rock, Kenneth W. Germans from Russia in America: the First Hundred Years. Fort Collins, CO: Germans from Russia in Colorado Study Project, Dept. of History, Colorado State University, 1976.

—. "'Unsere Leute': the Germans from Russia in Colorado.” The Colorado Magazine 54, 2 (Spring 1977): 155-183. 
Stumpp, Karl. The Emigration from Germany to Russia in the Years 1763 to 1862.

Lincoln, NE: American Historical Society of Germans from Russia, 1973.

\section{Web Sites}

American Social History Project/Center for Media and Learning, City University of New York, and the Center for History and New Media, George Mason University. "History Matters: the U.S. Survey Course on the Web." http://www.historymatters.gmu.edu/d/5078

Colorado Digitization Program, Digital Audio Working Group. “Digital Audio Best Practices Version 1.2.” Colorado Digitization Program. http://www.cdpheritage.org/resource/audio/documents/CDPDABP_1-2.pdf

Colorado State University Libraries. "Germans from Russia Collection.” http://lib.colostate.edu/gfr/

Western States Digital Standards Group, Digital Imaging Working Group. "Western States Digital Imaging Best Practices Version 1.0.” Colorado Digitization Program. http://www.cdpheritage.org/resource/scanning/documents/WSDIBP_v1.pdf Western States Digital Standards Group, Metadata Working Group. “Western States Dublin Core Metadata Best Practices Version 2.0.” Collaborative Digitization Program. http://www.cdpheritage.org/resource/metadata/documents/WSDCMBP.pdf U.S. Census Bureau. “American FactFinder.” http://factfinder.census.gov/home/saff/main.html?_lang=en 
Received: July 15, 2005 